a flow directed approximately towards the eastnorth-east, the drogue at $1,000 \mathrm{~m}$. averaging about 0.2 knot (about $10 \mathrm{~cm}$. $/ \mathrm{sec}$.) and that at $2,000 \mathrm{~m}$. about 0.1 knot. The second method consisted of taking normal hydrographic stations down to $3,000 \mathrm{~m}$. at the four corners of a square of 10 miles side, and computing the velocity perpendicular to each side of the square relative to that at $3,000 \mathrm{~m}$. The results indicated an apparent flow into the square across one pair of opposite sides and outwards across the other pair of sides. Mr. Crease suggested that this surprising result might be due to tidal changes in the slopes of the isobaric surfaces, the whole four stations having been occupied in a period of a little more than twelve hours. The third method employed a new technique, analogous to the use of an inverted radiosonde. A supersonic transmitter, emitting a 'ping' every few seconds, was attached to a type of parachute, so that it sank slowly through the water at a rate of about $250 \mathrm{~m}$./hr. Its position was fixed at intervals by sound-ranging, the pings being received by four hydrophones, one suspended below the ship and the other three below sono-radio buoys, which were moored to the bottom by piano wire, and which transmitted the received signals to the ship. The relative positions of the buoys and the ship were fixed by radar. The results showed a current in the same direction as that indicated by the drogues, but of a greater magnitude: about $0.5 \mathrm{knot}$ down to $1,200 \mathrm{~m}$. and decreasing at greater depths.

The discussion which followed reflected the interest aroused in the new theoretical and experimental approaches. In reply to suggestions on the sinking transmitter technique, Mr. Crease said that the design of a transmitter which would remain for a long period at a constant depth was being considered. Reference was made to the rotating model experiments of Von Arx at Woods Hole, Massachusetts, in which a basin of paraboloidal shape is used, providing for the variation of Corolis parameter with latitude, and boundaries having the outlines of the actual ocean boundaries in the northern hemisphere are inserted. Air streams over the model simulate the atmospheric wind systems, so that these experiments are a study of the wind-driven ocean circulation and in a sense are complementary to the 'dish pan' experiments, which have been concerned with circulations arising from processes of heating and cooling. While much remains to be learned about deep-water movements and the part they play in the general occanic circulation, it is clear that the subject is being attacked vigorously from several angles and that encouraging progress is being made.

K. F. BOWDEN

\section{LABORATORY ANIMALS IN THE UNITED STATES}

"T HE need for adequate standards and methods in the procurement of biological materials for research, assaying, testing and teaching"-to quote Dr. Orson N. Eaton-has been recognized for many years. The biological materials referred to are laboratory animals, and the need has, since the Second World War, become pressing in nearly every country in the world. The first action on a national scale was taken by the British Medical Research Council, which set up the Laboratory Animals Bureau in 1947. Five years later, in 1952, the Division of Biology and Agriculture of the American National Research Council, in consultation with government, university and industrial representatives, created an Institute of Animal Resources, and appointed Dr. Eaton as its executive secretary.

This was not the first American organization to make its main purpose the study of problems connected with laboratory animals. In 1950 a private and voluntary group of veterinarians and others interested in the provision and use of animals for scientific work formed an Animal Care Panel. This Panel has met every year from 1950 onwards for the purpose of receiving communications from its members, and these communications, together with the inevitable and stimulating discussions, are reproduced as proceedings. The proceedings are circulated only to members of the Panel, which is unfortunate, for much of their contents deserves wider publication; but the financial resources of the group are limited, and wider publication would presumably be beyond them.

There was a need, therefore, for the Institute of Animal Resources, with its official backing, both moral and material, and the choice of a distinguished geneticist as its executive secretary was a good one. All problems relating to laboratory animals are not genetical, and the Board of the Institute represents many other interests; but as the work of the Institute progresses, genetics will become increasingly important, and it is well that such developments can be expertly anticipated.

The work of the Institute is complementary to that of the Animal Care Panel, and since one finds that many names on the Board of one are among the membership of the other, close collaboration between the two can be assured. In addition to Dr. Eaton as executive secretary, the membership of the Executive Board of the Institute is made up as follows: P. B. Armstrong, Marine Biological Laboratory, Woods Hole; N. R. Brewer, Central Animal Quarters, University of Chicago ; T. C. Byerly, U.S. Department of Agriculture ; G. B. Coursen, General Biological Supply House, Chicago; A. E. Earl, Ciba Pharmaceutical Products; H. G. Herrlein, Rockland Farms; G. E. Jay, jun., National Institutes of Health; D. Jenkins, Chemical Corps Biological Laboratories; G. W. Kidder, Amherst College; C. G. King, Nutrition Foundation; W. Landauer, University of Connecticut; C. C. Little, Jackson Memorial Laboratory; R. C. Percival, Lederle Laboratories; and C. A. Slanetz, College of Physicians and Surgeons, Columbia University.

The aims of the Institute are : (1) to survey and list existing sources of animal stocks used in biological (including agricultural, medical and industrial) research, testing and assaying; and to determine the consumers and the volume of demand for such material; (2) to perpetuate this activity by taking periodic inventories and keeping a live master registry of those sources, for distribution to all interested persons and groups of consumers (for example, research laboratories, academic institutions, government agencies, industrial and trade establishments, etc.); (3) to promulgate scientific standards of definition, terminology and tolerated variability in regard to genetic constitution, nutrition, freodom from disease, housing conditions and maintenance for the major groups of animals in use ; (4) to act as a liaison centre on information regarding the detection, preservation and perpetuation of new or old strains 
of special importance for specific problems (for example, cancer) ; (5) to devise measures for ensuring adequate supplies of needed animal stocks in states of emergency (war, epidemics, etc.); and (6) to assist in the organization and facilitation of the international exchange of needed animal stocks.

The first publication of the Institute is a "Handbook of Laboratory Animals"*. This handbook has a page on genetics, by Dr. George E. Jay, jun. ; a page and a half on nutrition, by Dr. Charles A. Slanetz; a page on diseases of laboratory animals, by Dr. N. R. Brewer, followed by twelve pages summarizing the more common infections of a wide variety of species; an extensive table of sources of animal supply ; three pages on the uses of laboratory animals, with an extensive bibliography of uses; a short selection of general references; a table of users of laboratory animals; and a brief note on the importance and desirability of international exchange, both of information and of strains of animals of particular interest, which we in Great Britain can whole-heartedly endorse.

The main part of the handbook is occupied by the two tables, which have been compiled from the answers to questionnaires sent out by the Institute. The table of sources of animal supply is subdivided by species, and covers mice, rats, guinea pigs, rabbits, hamsters, dogs, monkeys, chicks and a wide variety of miscellaneous animals. There are columns showing strain, original source, breeding system, description, diet, disease control measures, uses and productive output, against each source of supply, which includes both laboratories and commercial breeders and suppliers. Although this list is far from complete for the country as a whole, and probably represents only a minority of total sources, it is formidable, and will undoubtedly be an immensely useful catalogue for any scientific worker wishing to select the most suitable animals for his researches. The tabulation is clear, and most of the information essentially useful. (A counterpart of this table is the "Laboratory Animals Bureau Catalogue of Uniform Strains maintained in Great Britain".) Further additions to the table have been promised, and any approach towards comprehensiveness will certainly enhance its value.

The list of uses of laboratory animals is certainly very incomplete, but, taken in conjunction with the table of sources, is a worth-while guide. Its expansion in subsequent issues would make it a useful reference index.

The second table, listing users of laboratory animals, contains information essential to the functioning of the Institute, but it is harder to see what interest it can have for others. Had it been necessary to show that the Institute was in fact well occupied, its inclusion in the handbook might have been justified, but the rest of the handbook is already sufficient evidence.

Such criticism of the Institute's work may appear ungenerous, but this would be a false impression. The Institute has undertaken a task, both of urgent necessity and of a complexity incomparably greater than in Great Britain, where the numbers of laboratories, of scientific workers and of animals used are so much smaller. It has tackled the problem with the vigour to be expected of our American colleagues, and the handbook, produced within two years of the

- Handbook of Laboratory Animals. (Pub. No. 317 of the National Academy of Sciences-National Research Council.) Prepared by the Institute of Animal Resources. Pp. v +77. (Washington, D.C., 1954.) 1.25 dollars. establishment of the Institute, is ample tribute to its competence and industry. Only one who has faced similar tasks elsewhere can appreciate how much thought and work went into this enterprise, and we look forward with ergerness and confidence to further publications from the same source.

\section{PROFESSIONAL STATUS OF MANAGEMENT}

A

WELL - KNOWN management consultant, Colonel L. Urwick, discusses in a small booklet* the question as to whether management is or is not regarded as a profession, and puts forward the view that the problem is not wholly academic or a matter of words. It can have considerable influence on such questions as whether or not during the next few years Britain will be able to pay its debts or must face a falling standard of life for its people. All that is necessary to establish the claim of management to professional status is to prove that it involves some branch of learning; in other words; that there is a body of knowledge bearing on the activity of management which can be taught and learned. In 1951 there were nearly seven hundred educational institutions in the United States awarding degrees at university standard in management subjects ; the number of university students 'majoring' in this field was more than 370,000 , and just over eighty thousand degrees were awarded.

In Great Britain the figures were proportionately much smaller; but a number of universities have degree courses in management. An intermediate examination in management subjects has been established, and it is national policy that technical colleges should provide facilities for those who wish to prepare for it. If there is no body of knowledge bearing on management which can be taught and learned, all these activities are meaningless. On what then, asks Colonel Urwick, is the resistance to this conclusion among certain business men founded ? The suggestion that management is becoming professionalized seems to many 'practical business men' to threaten with the 'theorizing' that they so much dislike the very area which they had previously regarded as the special citadel of practicality. Secondly, many men in responsible positions to-day are wholly innocent of any formal preparation for their tasks. They have learned the technique and customs of their particular trade or industry by 'experience'.

It is always difficult for the individual to resist the conclusion that the process which launched his peculiar abilities upon the community was wisely conceived. The tendency to become laudator temporis acti and exaggerated loyalty to 'the old school' have similar roots in the eternal fidelity of human nature to itself. The very suggestion of new and improved methods of training which will systematize and shorten the acquisition of experience seems to many a direct threat to their personal integrity.

Others again are concerned lest, if young men who have not yet won their spurs are allowed to study the art of management, they will become overimpressed with their own theoretical knowledge. There is some truth in this. Most young men under twenty-five who have had the benefit of a higher * Is Management a Profession ? By L. Urwick. Pp. 27. (London :
Urwick, Orr and Partners, Ltd., 1954.) 